\title{
The Application of Solar Cells for Water Filtration System
}

\author{
Bancha Sreewirote $^{1}$, Nuchtita Suttisinthong ${ }^{1}$ and Atthapol Ngaopitakkul ${ }^{2}$ \\ ${ }^{1}$ Department of Electrical Engineering, Faculty of Engineering, Thonburi University, Bangkok, Thailand \\ ${ }^{2}$ Department of Electrical Engineering, Faculty of Engineering, King Mongkut's Institute of Technology Ladkrabang, Bangkok, Thailand
}

\begin{abstract}
This paper explores the importance of renewable energy technologies to support global energy policy and helps to generate enough electricity to meet the demand. The system is used to convert solar energy to use with water filtration system to study the feasibility of installation in rural areas and the quality of drinking water must be standardized. Calculate the size and coordinates of the solar cell system has been proposed, including the study of the value of investment in system installation, the break-even point of investment has been introduced.
\end{abstract}

\section{Introduction}

Today, renewable energy technologies play an essential role in the household, economic and national level to mitigate the effects of current global warming. In energy point of view, it is another way to help country achieving the energy security; to have enough electricity to run and have low energy production costs due to lower energy imports. One of the most popular alternative energy sources that are suitable for Thailand's geography and climate is an electrical power generated by solar energy using solar cells. The use of solar panels to generate electricity helps the central unit to be efficient and stable. It must consist of effectively electronic control and energy storage units.

At present, there are many studies on the development of solar power conversion systems. In [1] the comparison of solar and diesel power generation has been studied and shown that solar power generation system has a lower cost per $\mathrm{kWh}$ for the case study in Iran considering low power consumption areas, able to compete with its old rivals.

The maximum power point technique (MPPT) has been implemented in [2] to extract maximum power from photovoltaic (PV) panel connected with the high voltageboosting converter and interleaved boost converter and conclude that the purposed topology can be increase voltage gain, reduce current ripple and reduce voltage stress on switches.

The development of solar panel system installed on seawater condition presents in [3], floating units support the PV and MPPT units, the tile angle is essential, should be less than the latitude angle of the location. Only considering the high solar irradiance for the solar generation system may not be enough. The study of the relationship between unit electricity cost and power deviation ratio investigated in [4]. Accurate prediction of solar power generation for supply-demand planning in an electrical grid is necessary. The daily prediction model has proposed [5] based on the PV output formula with a correction factor and uses weather forecast information.

The control unit is essential for the system to work accurately and efficiently convert solar energy into electricity and low electrical losses. In [6] discusses the design and controlling technique of a buck-boost converter for 50-100 W solar panels for household's apparatus. The presented Fuzzy logic control in case of the desired output voltage and the target ripple level are great regulated. The MPPT implementation in [7] was comparing the proposed MPPT algorithm in hardware and the simulation result by MATLAB. The automatically change the duty cycle technique has been investigated to maximize the power at any isolation, temperature and load condition.

In this paper will present an application of solar energy conversion to generate electricity for the use of water purifiers to provide hygienic and convenient to people living in a wilderness area that has limited electrical power, study the optimal size and number of PV installation including the value of an investment.

\section{System Under Study}

The system is designed to convert solar energy into electricity for use in water filtration systems. The energy used in the two major parts are the 750-Watt DC motor pump and Ultra Violet (UV) part for sterilization. The diagram of solar cell application circuit for water filtration system is depicted in Figure 1. 


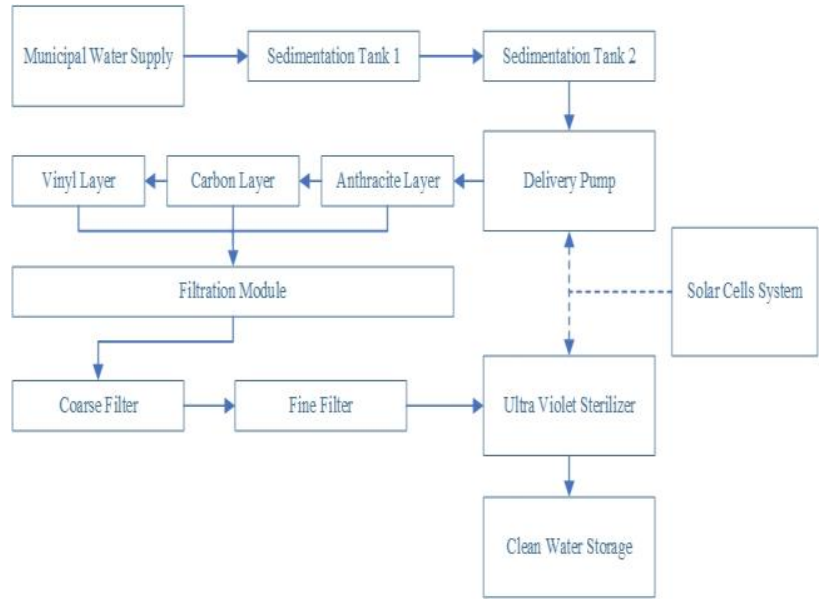

Figure 1. Solar cell application circuit for water filtration system.

Evaluating the right size for the solar panel's operation leads to an estimate of the size of the solar conversion system, as well as the design of other devices in the system, to suit the electrical energy requirements of the day. The calculations will need to back up in case of unexpected weather condition. The simplify calculations by taking the electrical losses and the performance of the primary equipment into account, solar panels have a $90 \%$ efficiency and wiring losses of $3 \%$. If the installed system at an average temperature of 30 degrees Celsius and completed wiring, the power input to the load from a 75watt solar panel is 65.45 watts, and then multiplied by the
Peak Sun Hours (PHS) value, that is the period of significant solar radiation and cloudless, an active load in the system are described in Table.1.

Table 1. Active Loads in The System.

\begin{tabular}{|c|c|c|c|}
\hline \multicolumn{5}{|c|}{ Loads in the System } \\
\hline Loads & $\begin{array}{c}\text { Power } \\
\text { (Watts) }\end{array}$ & $\begin{array}{c}\text { Usage time } \\
\text { (hr./day) }\end{array}$ & $\begin{array}{c}\text { Energy } \\
\text { Consumption } \\
\text { (W.hr./day) }\end{array}$ \\
\hline $\begin{array}{c}\text { DC water } \\
\text { pump }\end{array}$ & 750 & 3 & 2250 \\
\hline UV Sterlizer & 30 & 3 & 90 \\
\hline
\end{tabular}

From the DC pump that required $24-48$ volts, 750 watts and 11.5 amps and 30 watts UV system. The electricity consumed calculation each day leads to the selection of 14 panels of 75 watts, 17 volts, 4.45 amps. The installation of solar panels is divided into 3 parts as follows. The overall solar conversion system has been shown in Fig. 2 .

- The required voltage is $24-48$ volts, separate the solar panel into three sets of 4 solar panels each, connected in series acquiring 68 volts and 4.45 amps each module.

- The current requirement of $11.5 \mathrm{amps}$, connect those three modules in pillared configuration to achieve 13.35 amps.

- The remaining two panels are serialized to provide the energy for UV sterilization unit.
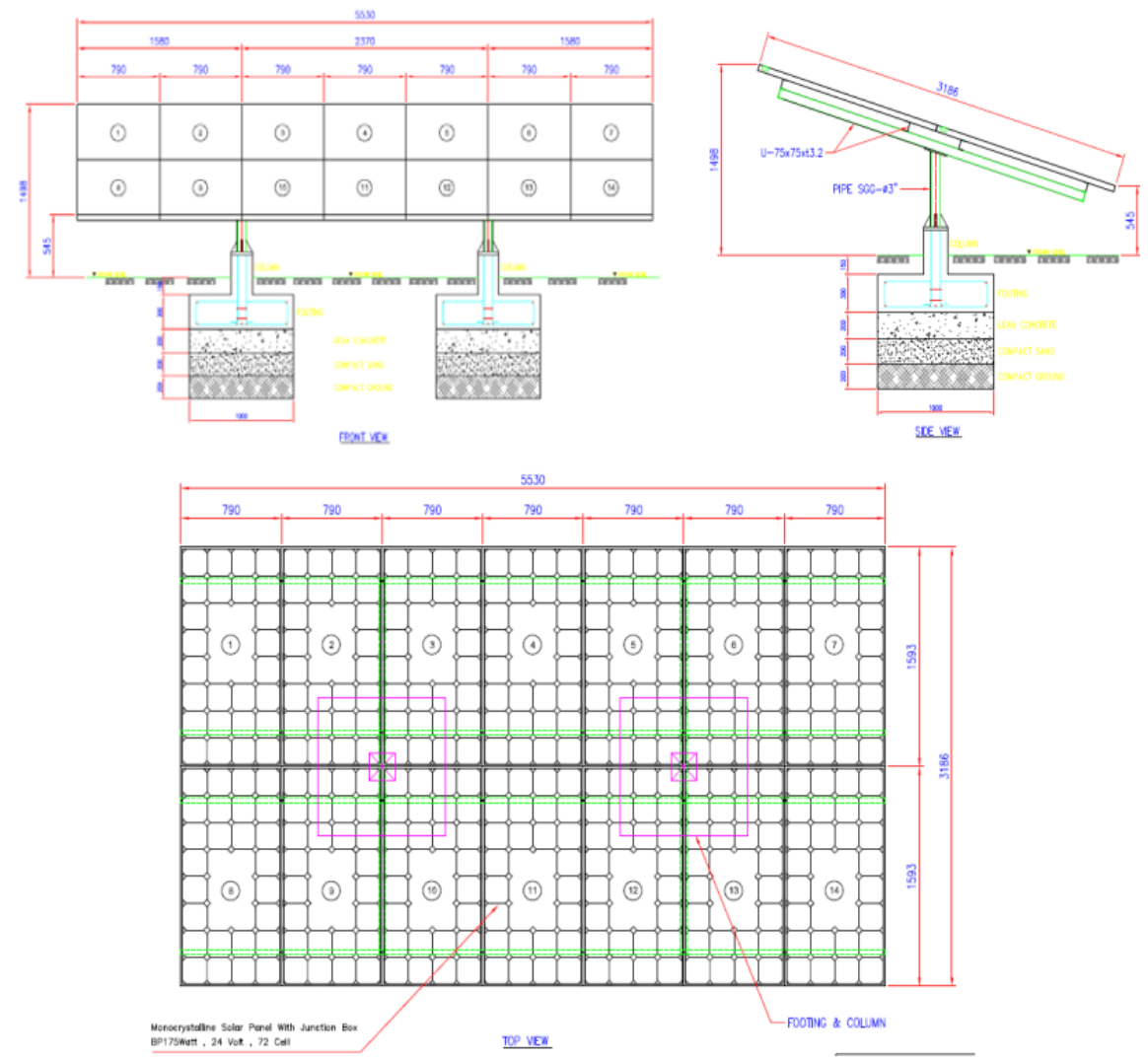

Figure 2. Configuration of the solar energy conversion system. 


\section{Result}

In the experiments of solar energy conversion system to measure the voltage produced by the solar panel. The solar panels used in this experiment are the 75 watts Monocrystalline type. The 14 panels performed the maximum voltage at 47.46 volts; the measurements start from 06.00 am to $6.00 \mathrm{pm}$ for two days. The results of panels temperature, generated voltage and current per hour, and PH value of unfiltered and filtered water are shown in Figure 3-5 respectively.

Figure. 3 and 4 shows the relationship between the solar panels. It can be analyzed that the voltage and current level depending on the temperature and the intensity of sunlight. Observe that the time between 6.00 am and $7.00 \mathrm{am}$, the temperature and light intensity was low leads voltage and current becomes low level. When the time is $11: 00$ am to $14: 00 \mathrm{pm}$, the highest range of temperature and light intensity of the day, causes the highest voltage and current production of the day. Therefore, it can be concluded that the voltage and current are both varied by the intensity of the sunlight.

In Figure 5, can be seen on a day of testing, the $\mathrm{PH}$ value of unfiltered water is $\mathrm{PH}$ is about 7.4-8, which hard water, should not consume. When the water is filtered, the $\mathrm{PH}$ value of the water is about 7.01-7.03, which is drinking water.

There are about 400 teachers and students at schools in the experimental area who need to drink about 1.5 liters of water a day, therefore the water needs about 600 liters/day. For consuming about 800 liters/day, the consumption of water for drinking and consumption approximately 1,400 liters per day. The water pump system through the solar water system able to be pumped, filtered, and keep into the water tank up to 1,000 liters in an hour, so use 3 hours a day (3,000 liters) is enough for each day.

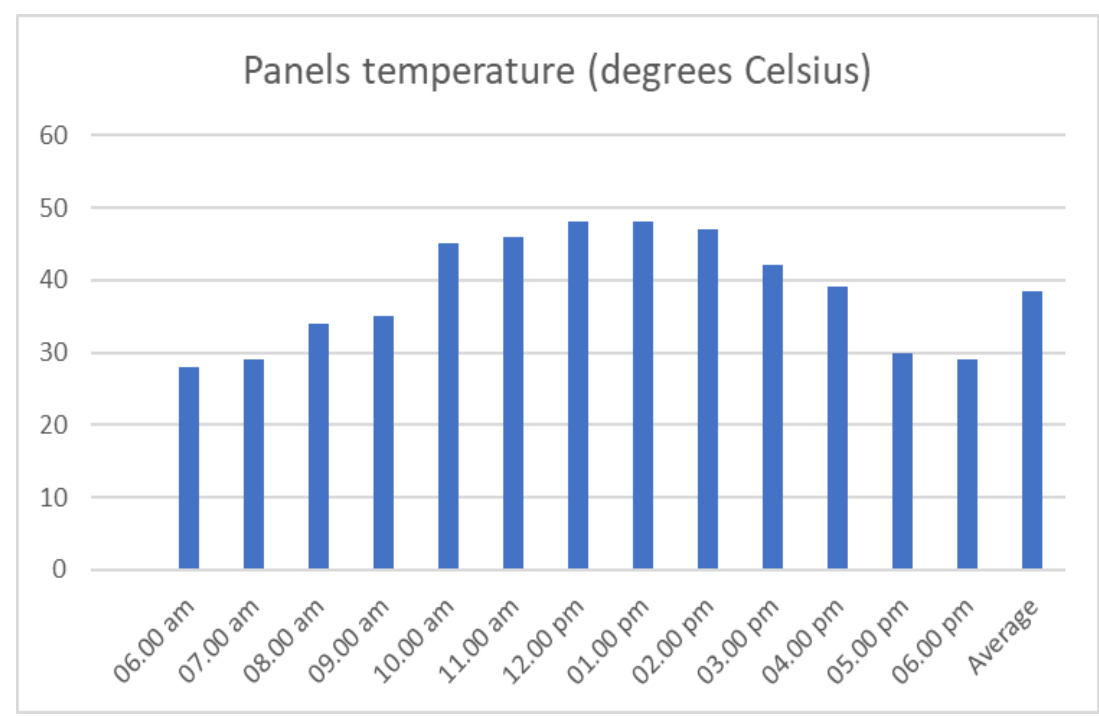

Figure 3. Panels temperature.

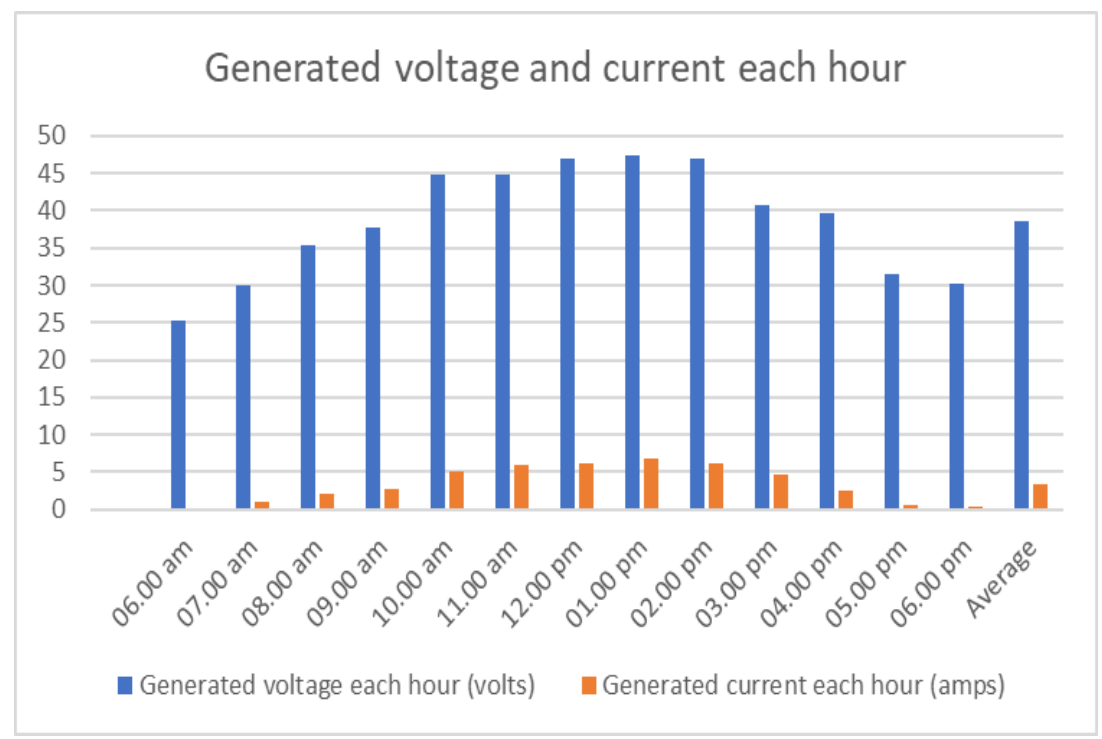

Figure 4. Generated voltage and current. 


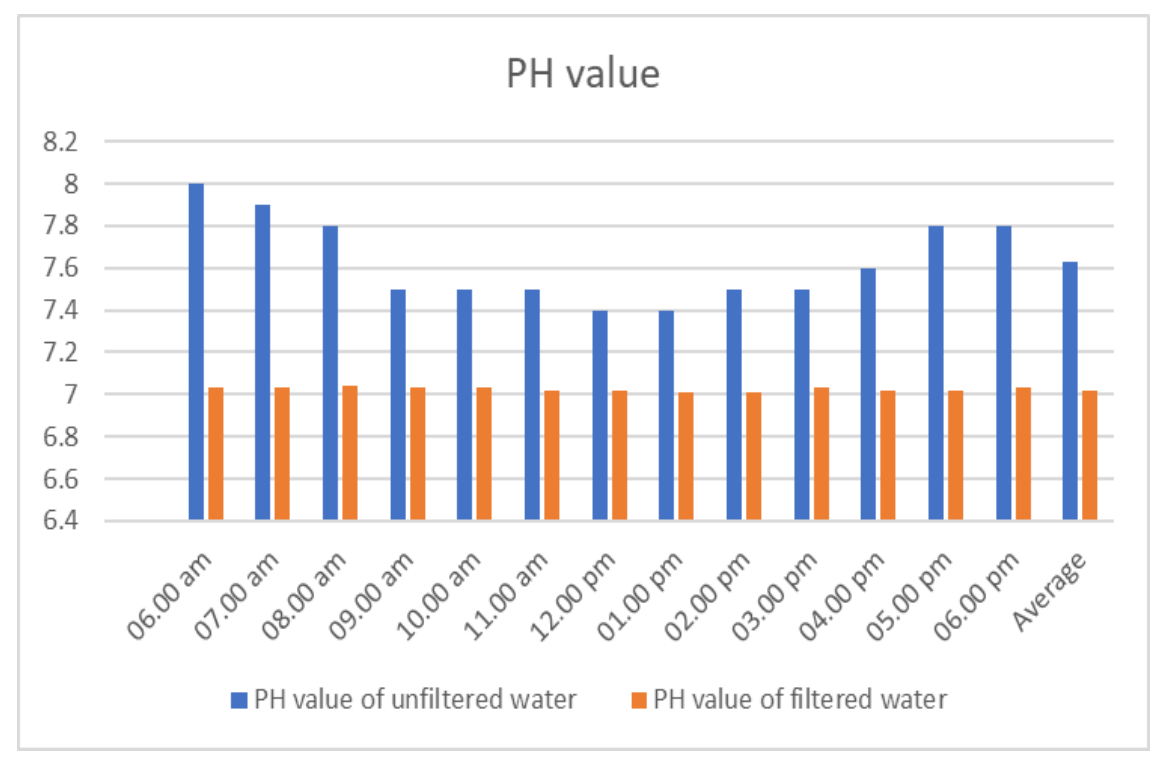

Figure 5. $\mathrm{PH}$ value.

\section{Economic Analysis}

Calculating the break-even point of investing in solar water filters. Starting from the compilation of the main materials for the whole test, compared with the reduced electricity compared to conventional water filters. The costs of equipment for installation is shown in Table 2.

Table 2. Equipment and installation cost.

\begin{tabular}{|c|c|}
\hline Device list & Costs (USD) \\
\hline 2 Water tank & 187.85 \\
\hline Water Filter & 2348.15 \\
\hline DC 24-48 volts 750 watts Water pump & 297.42 \\
\hline 75 watts Solar panel (14 panels) & 1314.90 \\
\hline Steel rod & 234.80 \\
\hline PVC pipe & 78.26 \\
\hline Delivery cost & 156.53 \\
\hline Other devices & 62.61 \\
\hline Labor cost & 313.06 \\
\hline Total cost & 4994.42 \\
\hline
\end{tabular}

Experimental analysis of break-even point, the investment cost approximately 4,994.42 USD, to generate electricity up to 1,050 watts per hour. If in a day with 7 hours average sunshine, the energy could produce up to 7,350 watts per day. Electricity cost of Thailand is divided into three parts.

- Electricity: 0.11 USD per Unit

- FT: 0.01 USD per Unit

- VAT 7\%: 0.0008 USD per Unit

While, Unit of electricity means usage of 1,000 watts of electricity for one hour. In summary, if you use one or 1,000 watts of electricity, a net electricity cost is 0.123 USD. Solar cells generate 7,350 watts of electricity per day, which is equivalent to 0.9 USD. Therefore, the break-even point is about 15.48 years to 16 years.

\section{Conclusion}

This research is a feasibility study for the installation of a solar energy conversion system for the application of water filtration systems to the school in the rural area. The results show that solar renewable energy systems are feasible to install in the provinces are in Thailand, which is the tropical country with higher average duration of sunshine than world standard. Also, the system is economically viable and has a short payback period. The quality of drinking water is appropriate for the health of people in the area.

\section{Acknowledgement}

The authors wish to acknowledge the financial support received from the Faculty of Engineering Thonburi University Research Fund.

\section{References}

1. M. Mohamadi, E. Roshandel and S. M. Gheasaryan, "A comparison of implementation of solar and diesel power generation for a case study in Kaloo," 2017 IEEE 4th International Conference on Knowledge- 
Based Engineering and Innovation (KBEI), Tehran, 2017, pp. 0114-0119.

2. C. Karuppanasamy and A. Rajendran, "Embedded control of advanced power converters fed electrical motor drive for solar power generation system," 2017 2nd International Conference on Communication and Electronics Systems (ICCES), Coimbatore, 2017, pp. 860-865.

3. S.F. Hui, H.F. Ho, W.W. Chan, K.W. Chan, W.C. Lo and K.W.E. Cheng, "Floating solar cell power generation, power flow design and its connection and distribution," 2017 7th International Conference on Power Electronics Systems and Applications - Smart Mobility, Power Transfer \& Security (PESA), Hong Kong, 2017, pp. 1-4.

4. Ahammad and K.K.H. Dia, "Impact of power deviation ratio on selection of sites to build solar power generation system," 2017 4th International
Conference on Advances in Electrical Engineering (ICAEE), Dhaka, 2017, pp. 455-459.

5. J. G. Kim, D. H. Kim, W. S. Yoo, J. Y. Lee and Y. B. Kim, "Daily prediction of solar power generation based on weather forecast information in Korea," in IET Renewable Power Generation, vol. 11, no. 10, pp. 1268-1273, 2017.

6. W. Wahab, "Design and simulation of an output voltage controller for solar power (PV) application using fuzzy logic controller," 2017 15th International Conference on Quality in Research (QiR) : International Symposium on Electrical and Computer Engineering, Nusa Dua, 2017, pp. 420-424.

7. S. Gautam, D.B. Raut, P. Neupane, D.P. Ghale and R. Dhakal, "Maximum power point tracker with solar prioritizer in photovoltaic application," 2016 IEEE International Conference on Renewable Energy Research and Applications (ICRERA), Birmingham, 2016, pp. 1051-1054. 